\title{
Review and Analysis on Effect of Control Systems in Sales Organization Performance
}

\section{통제시스템이 판매조직 성과에 미치는 영향에 관한 검토 및 분석}

Seok-Young Lee ${ }^{1}$

이석영 1

${ }^{1}$ Professor, Department of Management, Sungshin Women's University, South Korea, sylee@sungshin.ac.kr

\begin{abstract}
Based on organizational control theory and agency theory, this study examined how to link control systems to compensation contracts to maximize organizational performance. The main results derived from this study can be summarized as follows. First, depending on types of sales organization, their emphasis on a salesperson's effort is different. Especially in high-end sales organizations, organizational performance is driven by salesperson's customer-focused services rather than standardized routine services. Thus, salespeople need to be more empowered to exert higher level of creative effort. In this case, they need to consider combining the low level of monitoring with monetary incentives based on output. Second, in low-end sales organizations, they may consider using behavior control with a high level of monitoring. However, in case that the measurable outcome is available, they need to use both behavior control that relies on higher level of monitoring and outcome control that is based on output. Third, in high-end organizations, when they use both behavior control and outcome control, the negative effect of monitoring dominates the positive effect of monetary incentives on performance. The results suggest that the interaction effect of the two control systems is negative. Therefore, this implication is beyond simply substituting one for the other or complementing each other.
\end{abstract}

Keywords: Organizational Control Theory, Agency Theory, Compensation Contract, Salesperson, Behavior Control, Outcome Control

요약: 본 연구에서는 조직통제이론과 대리인이론에 입각하여 통제시스템과 보상계약의 연계를 어떻게 하는 것이 조직의 성과를 극대화할 수 있는지에 대해 검토한다. 본 연구의 주요 결과를 요약하면 다음과 같다. 첫째, 판매조직의 유형에 따라서 그 조직의 산출물에 지대한 영향을 미칠 수 있는 판매직원의 노력은 상이하게 정의될 것이다. 특히 고객서비스가 중요한 하이엔드 판매조직에서는 판매직원의 업무 중 표준화된 일상적 서비스보다는 고객지향적 서비스를 이끌어내는 것이 중요할 것이며, 이를 위해서는 감독자가 낮은 수준의 관리감독을 유지함으로써 판매직원의 자율성(autonomy) 증대를 위한 통제방식과 그에 따른 보상계약을 체결하는 것이 유리할 것이다. 둘째, 로우엔드 판매조직에서는 단순히 감독자의 관리감독 기능을 강화하는 행위통제 방식에 의존하는 것도 고려해 볼 수 있으며, 판매직원의 산출물을

Received: March 28, 2021; 1st Review Result: May 11, 2021; 2nd Review Result: June 25, 2021 Accepted: July 31, 2021 
정확히 정의할 수 있다면 높은 수준의 관리감독을 유지하는 행위통제방식과 더불어 결과통제로서 산출물에 입각한 금전적 유인을 제공하는 것도 의미가 있을 것으로 판단된다. 셋째, 하이엔드 판매조직에서 행위통제와 결과통제를 동시에 실행하는 경우 감독자의 관리감독의 수준이 성과에 미치는 부정적 영향이 금전적 유인으로 인한 긍정적 영향을 압도할 수 있기 때문에, 두 통제시스템 간의 상호작용 효과는 부(-)로 나타나게 된다. 이와 같은 두 통제시스템 간의 상호작용 효과는 선행연구에 의해 제기된 대체효과 또는 상호보완효과와는 상이한 것으로 해석할 수 있다.

핵심어: 조직통제이론, 대리인이론, 보상계약, 판매직원, 행위통제, 결과통제

\section{1. 서론}

조직통제이론에 의하면 통제는 행위통제(behavior control)와 결과통제(outcome control)로 분류되는데, 특정 과업과 관련하여 어느 통제시스템을 사용할 것인지 여부는 해당 과업의 결과에 대한 측정가능성(measurability)과 해당 과업을 수행하는 과정의 구체화 가능성(programmability)에 의해 결정된다[1]. 만약 과업을 수행함에 있어 그 과정을 구체적으로 정의하기 어렵지만 그 과업을 수행한 결과를 객관적으로 측정할 수 있다면, 그 과업을 관리함에 있어 결과통제를 사용하는 것이 적절할 것이다. 조직통제이론에서 행위통제와 결과통제가 별개의 통제시스템으로 이분법적으로 분류되고 있지만, 실제 현실에서는 두 가지 형태의 통제시스템이 동시에 활용되고 있다. 게다가 행위통제는 관리자의 관리감독(monitoring) 기능에 의해 지원을 받고 있다[2].

본 연구와 관련된 Sihag and Rijsdijk(2019), Wang, Dou, and Zhou(2012), Lo, Ghosh, and LaFontaine(2011) 등의 선행연구의 동향은 다음과 같다. 첫째, 대리인이론 관점에서는 두 가지 형태의 통제방식인 행위통제와 결과통제를 동시에 활용하는 경우에 대한 분석이 미흡하다고 판단된다. 둘째, 감독자의 관리감독이 각 통제방식과 관련된 원가와 효익에 미치는 영향을 구체적으로 검토하지 않았다. 셋째, 대리인이론과 조직통제이론 간의 연계성은 인지되었으나, 그러한 연계관계가 분석적으로 공식화되지는 못한 실정이다. 그러나 본 연구의 주된 목적은 복수의 통제시스템을 동시에 활용하여 파악한 성과측정치를 활용하여 조직구성원을 동기부여 함으로써 조직의 성과 극대화에 초점을 맞추고 있다. 이를 위해 본 연구는 먼저 행위통제와 결과통제에 관한 문헌적 검토를 수행한 후, 대리인이론에 입각한 분석적 모형을 활용해 감독자의 관리감독이 행위통제와 결과통제에 미치는 영향을 분석함으로써 판매조직의 성과관리에 대한 시사점을 도출하고자 한다[3-5]. 이와 같은 본 연구의 접근방법은 선행연구에서 구체적으로 고려하지 못했던 판매조직의 특성, 판매직원의 업무 특성, 판매직원 업무수행에서 요구되는 노력의 특성, 감독자의 관리감독 기능, 통제시스템의 역할, 보상계약의 설계 등의 상호작용 및 관계를 탐색하기 위한 구체적이고 공식적인 시도라는 점에서 선행연구와의 차별점을 찾을 수 있을 것이다.

본 논문의 구성은 다음과 같다. 제 2 장에서는 기존 문헌에 대한 검토를 통해 판매조직에서의 판매사원의 업무와 그 업무 수행에 요구되는 노력의 특성, 감독자의 관리감독이 판매직원의 성과에 미치는 영향, 금전적 유인이 판매직원의 성과에 미치는 영향, 감독자의 관리감독과 금전적 유인이 동시에 제공되는 경우 판매직원의 성과에 미치는 영향을 검토한다. 제 3 장에서는 제 2 장에서 검토한 쟁점사항을 대리인이론에 
입각한 주인-대리인 모형(principal-agent model)을 이용하여 분석적으로 논의한다. 마지막으로 제4장에서는 문헌적 검토 및 분석적 고찰에 입각하여 추출한 판매조직의 성과관리의 시사점을 종합적으로 제시한다.

\section{2. 문헌적 검토}

조직통제이론은 조직의 목표달성을 위한 수단으로 행위통제와 결과통제를 제시 하였다[1]. 구체적으로, 행위통제는 상급자의 하급자들에 대한 지시, 확인, 점검, 감시, 감독 등을 주로 포함하지만, 결과통제는 개인의 성과평가에 입각하여 금전적인 보상을 통한 유인을 제공한다[3][4]. Fatima and Azam(2017)에 의하면 어느 통제시스템이건 대리인문제를 완화하기 위해 사용될 수 있으며, 그 중 어느 통제시스템을 선택할 것인가는 수행하여야 할 업무의 성과평가 결과를 객관적으로 측정가능한지와 해당 업무를 어떻게 수행하여야 하는지에 대해 사전적으로 그 과정을 구체적으로 정의할 수 있는지에 따라 결정된다[1].

대리인이론 분석모형에 입각한 선행연구인 Lo, Ghosh, and LaFontaine(2011)에서는 대리인이 수행하여야 할 업무가 단일의 업무가 아닌 복수의 업무이며 그 업무 수행에 투입할 노력이 단순히 한 유형의 노력만이 아니고 복수의 상이한 노력이 요구되는 경우 대리인은 복수의 업무 각각에 대해 투입하여야 할 복수의 노력의 수준을 최적으로 결정하여 성과평가의 결과를 극대화하고자 하는 유인이 존재하기 때문에, 조직의 성과를 극대화하기 위한 통제시스템의 설계는 보다 복잡해질 수밖에 없다[5]. 본 장에서는 먼저 판매조직에서의 판매직원이 수행하게 되는 업무와 그 업무를 달성하기 위해 투입하여야 할 노력의 특성에 관해 살펴본 후, 감독자의 관리감독을 위주로 설계된 행위통제가 판매직원의 성과에 미치는 영향, 성과평가의 결과에 대해 금전적 보상을 제공하는 결과통제가 판매직원의 성과에 미치는 영향, 행위통제와 결과통제가 동시에 판매직원에 제공되는 통제시스템을 설계한 경우 두 시스템이 판매직원의 성과에 미치는 영향을 검토한다.

\section{1 판매직원의 업무와 업무수행에 요구되는 노력의 특성}

판매조직에서 판매직원의 업무는 고객지향적 서비스(customer-oriented service)와 표준화된 일상적 서비스(standard routine service)를 포함한다[4]. 여기서 고객지향적 서비스란 판매직원이 판매하고자 하는 상품/제품의 특징과 성능을 숙지하고 있어야 하며, 고객의 선호도를 기민하게 파악할 수 있어야 하며, 고객의 선호도와 고객이 원하는 제품의 특징을 대응시킬 수 있어야 하며, 각 고객에 대한 판매행위를 적절히 조정할 수 있어야 하며, 고객의 구매의사결정에 전향적으로 영향을 미쳐 고객의 재구매를 촉진하여야 하며, 궁극적으로 고객에게 만족스러운 서비스를 제공함으로써 고객을 장기적으로 유지하는 것이다[4]. 이와 같은 업무는 판매직원으로 하여금 의욕적이며 자발적인 태도를 요구한다.

그러나 표준화된 일상적 서비스는 고객의 방문 시의 적절한 환대, 고객의 질문에 대한 납득할 만한 응대, 매장 내에서 상품 재고의 정리 정돈 및 배치, 판매거래의 처리 등과 같은 사전에 정해진 절차를 숙련되게 수행할 것을 요구한다. 따라서 표준화된 일상적 서비스는 감독자의 지시를 적절하게 준수하는 것을 요구한다. 판매직원이 수행하여야 할 다양한 업무의 속성을 고려할 때, 고객지향적 서비스는 사전에 어떻게 수행할 것인지에 
대해 구체적으로 정의하기 어렵다. 그 이유는 상이한 고객들은 그들이 원하는 제품 및 서비스에 대해 이질적인 선호도와 기대를 가지고 있기 때문이다. 따라서 고객지향적 서비스는 판매직원들로 하여금 상당한 정도의 창의적인 노력의 투입을 요구하게 되며, 관리자는 각 판매직원이 그들의 판매 스킬을 어떻게 개선하고 있으며 고객과의 상호관계를 어떻게 유지하고 있는지를 항시 관찰하여 적절한 관리감독기능을 수행하는 것이 가능하지 않다[1]. 반면, 표준화된 일상적 서비스는 사전에 어떻게 수행할 것인지에 대해 구체적으로 정의하기 용이하며 일상적 노력의 투입을 요구한다.

따라서 판매직원의 일상적 노력의 투입은 창의적 노력의 투입에 비해 보다 훨씬 더 관찰가능한데, 이는 판매직원의 일상적 노력이 투입되었는지는 그들이 사전에 정해진 절차를 적절히 준수하였는지에 대해 평가하면 되기 때문이다[2]. 하이엔드 판매조직에 있어 고객지향적 서비스는 판매성과에 중요한 역할을 하기 때문에, 낮은 품질의 고객지향적 서비스는 매출을 개선하기 어려우며 기존 고객의 이탈을 유발할 것이다. 따라서, 쉽게 관찰 가능하지 않은 창의적 노력의 한계산출물(marginal output)은 용이하게 관찰 가능한 일상적 노력의 한계산출물에 비해 훨씬 높게 나타날 것이다[6].

\section{2 감독자의 관리감독이 판매직원의 성과에 미치는 영향}

전형적인 대리인이론의 주인-대리인 모형(principal-agent model)에서 대리인은 관찰 가능한 일상적 노력과 관찰 불가능한 창의적 노력 모두를 투입하여 복수의 업무를 수행하며, 각 유형의 노력 수준이 그의 기대보상에 미치는 민감도를 고려하여 그의 기대효용을 극대화할 수 있도록 상이한 업무에 투입할 각 유형의 노력을 배분한다[5]. 위임자인 주인은 최고의 산출물을 창출하기 위해 대리인이 그의 각 유형의 노력의 수준을 최적으로 배분할 수 있도록 보상계약을 설계한다. 따라서 판매직원의 고객지향적 서비스와 관련된 창의적 노력의 중요성이 부각되고 있는 판매조직일수록 주인은 대리인으로 하여금 창의적 노력에 대한 최적 수준의 투입을 유인할 수 있는 보상계약을 설계함으로써 조직의 성과를 극대화할 수 있다[7].

산출물과 관련된 금전적 유인이 존재하지 않는 경우, 판매직원은 감독자가 관리감독 (monitoring)을 통해 획득하게 되는 판매직원이 투입한 노력의 수준에 대한 시그널에 기초하여 보상이 이루어진다[4]. 이와 같은 감독자의 관리감독은 대리인인 판매직원이 투입한 창의적 노력에 대한 시그널보다 투입한 일상적 노력에 대한 시그널을 개선하는 효과를 가지게 된다. 그 이유는 감독자는 판매직원이 표준화된 일상적 서비스에 대해 사전에 정의된 지시사항을 어떻게 적절하게 준수하고 있는지에 대해 보다 쉽게 관찰하여 지시 및 점검할 수 있는데 반해, 감독자는 판매직원이 고객과의 관계형성 및 의사소통을 효과적으로 수행하고 있는지를 관리하고 감독하는 것은 용이하지 않기 때문이다[1][2]. 따라서, 감독자의 관리감독은 판매직원의 창의적 노력보다는 일상적 노력을 더 유발할 것이다. 고객지향적 판매조직에서 감독자가 낮은 수준의 관리감독을 수행하게 되면 조직의 성과에 긍정적인 영향을 미치게 되는 데, 이는 판매직원으로 하여금 자신의 의지에 따라 자신의 효용 극대화를 위해 일상적 노력과 창의적 노력 둘 다를 적절히 발휘하게 효과가 있기 때문이다[5].

그러나 감독자의 관리감독의 수준을 강화하게 되면, 판매직원의 일상적 노력의 수준을 증가시킬 수 있으나 판매조직의 성과에 결정적인 역할을 하는 창의적 노력의 수준은 최적의 수준에 미치지 못할 것이다. 따라서, 고객지향적 하이엔드 판매조직에서는 
판매직원의 일상적 노력의 한계산출물이 판매직원의 창의적 노력의 한계산출물에 비해 적기 때문에, 감독자의 관리감독의 수준을 증가시킴에 따라 감독자의 관리감독이 판매직원의 성과에 미치는 한계적 영향은 지속적으로 감소하게 된다[8]. 게다가 감독자의 관리감독이 최적 수준을 초과하게 되면, 판매직원은 창의적 노력 대신에 보다 일상적 노력의 투입에 집중하게 되며 이는 판매직원에 의해 투입되는 일상적 노력과 창의적 노력 간의 최적의 배분에서의 이탈을 초래하게 되어 궁극적으로 관리감독의 수준이 산출물에 미치는 한계적 영향은 부(-)로 나타나게 된다. 즉, 판매직원의 일상적 노력과 창의적 노력 간의 배분에 있어 왜곡의 정도가 심하면 심할수록 관리감독의 한계적 영향은 보다 더 부(-)의 효과를 나타낼 것이다[8].

게다가, 동기부여이론에 의하면 감독자의 관리감독은 창의적 노력을 다하고자 하는 판매직원의 내재적 동기부여에 악영향을 미쳐 결국 창의적 노력의 한계산출물을 감소시키는 결과를 가져온다[6]. 따라서 반복적이고 지루한 표준화된 일상적 서비스를 강조하게 되면 판매직원의 자발적인 동기부여 효과에 악영향을 미치게 되어 그들의 성과에 부정적인 효과를 가져오게 된다. Campbell, Epstein, and Martinez-Jerez(2011)는 느슨한 혹은 엄격한 수준의 관리감독은 종업원의 학습에 대한 동기부여에 영향을 미칠 수 있음을 시사한다[9].

따라서 감독자의 관리감독이 낮은 수준에서는 감독자의 관리감독이 판매직원의 성과 및 판매조직의 성과에 미치는 한계적 영향은 정(+)을 보일 것이나, 관리감독의 수준을 증가시킴에 따라 관리감독이 성과에 미치는 한계적 영향은 지속해서 감소할 것이다. 다시 말해, 최적의 관리감독 수준에 도달한 이후에 추가로 감독자의 관리감독의 수준을 증가시키게 되면, 관리감독의 부(-)의 한계효과는 지속적으로 증가하게 될 것이다. 따라서 감독자의 관리감독의 수준과 판매직원 또는 판매조직의 성과 간의 관계는 역의 $\mathrm{U}$ 자 형태를 보일 것이다[10].

\section{3 금전적 유인이 판매직원의 성과에 미치는 영향}

성과에 기초한 금전적 유인(performance-based monetary incentives)은 위험 회피적이며 노력의 투입에 대해 비효용을 느끼는 대리인으로 하여금 보다 높은 수준의 노력을 투입하여 보다 높은 수준의 산출물을 창출하도록 유도하기 위해 제공된다[4][5]. 게다가 보상계약에 금전적 유인을 포함하게 되면 노동시장에서의 역선택을 완화하는 효과가 존재한다[11]. 성과에 기초한 금전적 유인이 제공되면 보다 생산성이 높은 종업원들은 이를 선호하겠지만, 생산성이 낮은 종업원들은 이와 같은 성과급 제도하에서 그들의 미래 임금이 자신들의 유보임금(reservation wage)보다 낮을 것으로 예상하게 되어 그와 같은 성과급 제도하에서 일하는 것을 원치 않을 것이다[11]. 따라서 조직에서 조직구성원에게 성과에 기초한 금전적 유인을 제공하게 되면 조직구성원이 보다 높은 노력의 수준을 발휘하도록 유도함으로써 도덕적 해이(moral hazard) 문제와 더불어 보다 높은 능력을 보유한 종업원들을 유치하여 그들을 계속 유지할 수 있어 역선택(adverse selection) 문제를 한꺼번에 해결할 수 있다[11]. 따라서 Macho-Stadle and PérezCastrillo(2020) 등의 선행연구들은 금전적 유인과 성과 간의 정(+)의 관계를 제시하고 있다[7].

그러나 대리인들이 그들에게 제공된 금전적 유인제도를 자신들에 대한 불신(distrust)의 신호 또는 자신들이 투입한 노력의 결과가 실패로 판명되는 경우에 대한 처벌로 
받아들이게 되는 경우에는 금전적 유인이 항상 성과에 정(+)의 효과를 미치지는 못한다[2]. 따라서 종업원들은 조직이 자신들을 믿지 못한다고 인지하게 된다면 그들은 주인의 이익을 극대화하는 방식으로 행동을 취하지 않을 것이며, 따라서 창의적 노력의 투입에 소극적일 가능성이 높다[6]. 게다가 성과에 기초한 금전적 유인보상제도 하에서는 자신들의 성과를 부풀리고자 하는 부정행위가 가능하다[2]. 그러나 판매조직에서는 판매직원이 그들의 성과를 왜곡하기는 쉽지 않다. 왜냐하면 그들은 고객을 성공적으로 납득하여 구매를 하게 하거나 아니면 그렇지 못한 경우로 그들의 성과를 정의할 수 있기 때문이다. 판매직원들이 그들의 판매성과를 부풀리기 위해 불법행위에 관여할 가능성은 제한적이기 때문에, 금전적 유인이 판매직원의 성과에 부(-)의 영향을 미칠 가능성은 낮을 것이다[2].

\section{4 감독자의 관리감독과 금전적 유인이 판매직원의 성과에 미치는 영향}

마케팅 분야 선행연구에서 제기된 흥미로운 연구과제 중 하나는 감독자의 관리감독과 금전적 유인을 판매직원의 보상에 동시에 고려하였을 때 과연 이 두 요소가 조직의 목표달성에 있어 상승효과로 작용할 수 있느냐는 것이다[1][4][5]. 이와 관련하여 Fatima and Azam(2017)에 의하면, 특정 업무에 관련하여 사전에 어떠한 과정을 거쳐 그 업무를 적절하게 수행할 수 있는지에 대해 구체적으로 정의하기 어려우면서 그 업무의 성과를 객관적으로 측정 가능하다면, 이 경우에는 금전적 유인에 의한 결과통제시스템을 활용하는 것이 타당하다[1]. 반면, 업무를 성공적으로 완수하기 위해 그 절차 등의 과정을 비교적 용이하게 정의할 수 있지만 그 업무의 성과를 정확히 측정할 수 없는 경우에는 감독자의 관리감독에만 의존하는 행위통제시스템의 운용이 적합하다[1]. 따라서 Wang, Dou, and Zhou(2012)는 업무의 수행 절차를 구체적으로 정의할 수 있는 가와 수행하게 될 업무의 성과를 정확히 측정할 수 있는 가에 따라 판매조직에서 실행되고 있는 행위통제와 결과통제는 상호간 대체적이거나 아니면 상호 보완적일 수 있음을 시사한다 [4].

판매직원은 자신의 성과를 달성하기 위해 감독자가 관찰가능한 일상적 노력과 감독자가 관찰할 수 없는 창의적 노력을 동시에 발휘하여야 하며, 판매직원의 성과는 자신이 투입한 일상적 노력의 수준보다는 창의적 노력의 수준에 의해 결정되는 판매조직을 고려해보자. 이와 같은 판매조직에서는 감독자의 관리감독은 금전적 유인을 대체할 수도 없으며 또한 금전적 유인에 대한 보완적인 역할을 할 수 없다[10]. 그 이유는 감독자의 관리감독은 감독자가 관찰가능한 판매직원의 일상적 노력의 수준에 대한 시그널의 정확성을 개선할 수 있을 따름이지 그가 관찰할 수 없는 판매직원의 창의적 노력의 수준을 끌어낼 수는 없기 때문이다. 대리인인 판매직원이 일상적 노력과 창의적 노력을 동시에 투입하여 복수의 업무를 수행하는 대리인이론 모형에서 밝힌 바와 같이, 감독자의 관리감독의 수준과 판매직원의 성과 간의 관계는 역의 $\mathrm{U}$ 자형으로 나타난다[5]. 만약 판매직원의 성과에 기초하여 금전적 유인을 제공하게 된다면, 이는 판매직원으로 하여금 보다 높은 수준의 노력을 투입하도록 동기를 부여하게 되며 이는 상이한 업무 간에 그의 노력의 수준을 최적으로 배분하게 하는 효과가 있다. 따라서 감독자의 관리감독에 의존하는 행위통제에 추가로 금전적 유인을 제공하는 결과통제를 동시에 실행하게 된다면, 감독자의 관리감독이 갖는 한계 효익(marginal benefit)은 감소하게 된다[5]. 따라서 금전적 유인이 동시에 제공되는 경우에는 감독자의 관리감독의 한계적 영향은 금전적 유인 제공 대신에 행위통제에 의존하는 경우에 비해 보다 낮은 
수준에서 부(-)의 효과를 나타내게 되어, 궁극적으로 감독자의 관리감독의 최적 수준은 더 낮은 수준에서 결정될 것이다[10].

따라서 행위통제와 결과통제를 동시에 실행하는 경우 감독자의 관리감독의 수준이 성과에 미치는 부정적 영향이 금전적 유인으로 인한 긍정적 영향을 압도하기 하기 때문에, 두 통제시스템 간의 상호작용 효과는 부(-)로 나타나게 될 것이다. 이와 같은 두 통제시스템 간의 상호작용 효과는 Sihag and Rijsdijk(2019) 등에 의해 제기된 대체효과 또는 상호보완효과와는 상이한 것으로 해석할 수 있을 것이다. 이와 관련하여 제3장에서는 분석적 모형을 이용하여 구체적으로 논의한다[3].

\section{3. 대리인이론에 입각한 분석}

\section{1 분석모형 및 가정}

제 2 장에서 검토한 판매조직의 특성, 판매직원의 업무 특성, 판매직원 업무수행에서 요구되는 노력의 특성, 감독자의 관리감독 기능, 통제시스템의 역할, 보상계약의 설계 등의 상호작용을 파악하기 위한 본 연구의 분석모형은 대리인이론에 입각하여, 위험 중립적인 주인(principal)이 위험 회피적이며 투입한 노력의 수준에 대해 비효용을 가지는 대리인(agent)을 고용하여 업무를 위임하며 대리인으로 하여금 산출물을 창출하게 하는 조직에서의 주인과 대리인 간의 보상계약의 체결에 초점을 맞춘다. 본 연구의 분석모형에서 판매직원에 해당하는 대리인은 산출물을 창출하기 위해 일상적 노력 $e_{1}$ 과 창의적 노력 $e_{2}$ 을 투입하게 되지만, 조직의 경영자에 해당하는 주인은 대리인이 투입한 각 노력의 수준을 직접 관찰할 수 없다[7]. 대리인이 투입한 일상적 노력 $e_{1}$ 과 창의적 노력 $e_{2}$ 에 대해 대리인이 갖게 되는 효용원가함수는 다음과 같이 정의한다: $C\left(e_{1}, e_{2}\right)=c_{1} e_{1}^{2} / 2+c_{2} e_{2}^{2} / 2$.

대리인이 업무를 수행한 결과인 산출물 $x$ 는 대리인이 투입한 두 가지 유형의 노력의 수준에 의해 다음과 같이 결정된다고 가정한다: $x\left(e_{1}, e_{2}\right)=e_{1}+\lambda e_{2}+\varepsilon_{x}$. 이 식에서 $\varepsilon_{x}$ 는 오차항으로 평균은 0 이며 분산은 $\sigma_{x}^{2}$ 인 정규분포를 따르는 것으로 가정하며, $\lambda$ 는 양(+)이며 창의적 노력에 대한 산출물의 민감도이다. 주인은 대리인이 투입한 두 가지 유형의 노력의 수준에 관한 정보를 직접 관찰할 수는 없지만, 감독자의 관리감독을 통해 대리인의 행위에 관한 시그널(signal) $y$ 를 획득할 수 있다. 대리인의 행위에 대한 관리감독 시그널 $y$ 은 다음과 같이 정의한다: $y\left(e_{1}, e_{2}\right)=e_{1}+e_{2}+\varepsilon_{y}$, 이 식에서 $\varepsilon_{y}$ 는 오차항으로 평균은 0 이며 분산은 $\sigma_{y}^{2}(m)$ 인 정규분포를 따르는 것으로 가정한다[7].

감독자의 관리감독의 수준인 $\mathrm{m}$ 을 보다 증가시키면 증가시킬수록, 주인은 그만큼 대리인이 투입한 노력의 수준과 관련하여 보다 더 정확한 관리감독 시그널을 확보하게 되며, 이를 식으로 표현하면 다음과 같다: $d \sigma_{y}^{2}(m) / d m<0, d^{2} \sigma_{y}^{2}(m) / d m^{2} \geq 0$. 이와 같은 대리인의 행위에 대한 관리감독 시그널의 확보는 주인에게 원가를 발생하게 되는데, 그 원가함수 $D(m)$ 는 다음과 같은 특성을 갖는다: $d D(m) / d m>0, d^{2} D(m) /$ $d m^{2} \geq 0$. 산출물 $x$ 와 관리감독 시그널 $y$ 간의 공분산 $\sigma_{x y}$ 는 양(+)인 것으로 가정한다[7].

본 연구의 분석모형에서는 산출물 $x$ 과 대리인의 행위에 관한 관리감독 시그널 $y$ 는 대리인의 일상적 노력 $e_{1}$ 의 수준에 대해 동일한 민감도를 가지는 것으로 가정한다. 대리인의 행위에 관한 시그널 $y$ 는 대리인이 투입한 일상적 노력 $e_{1}$ 의 수준을 
평가하는데 유용한 성과지표이다. 만약 대리인이 일상적 노력 $e_{1}$ 만을 투입하고 창의적 노력 $e_{2}$ 를 투입하지 않는 경우, 행위통제는 결과통제와 동일한 결과를 가지게 되는 것을 의미한다. 반면, 본 연구의 분석모형에서는 산출물 $x$ 과 대리인의 행위에 관한 관리감독 시그널 $y$ 는 대리인의 창의적 노력 $e_{2}$ 의 수준에 대해 상이한 민감도를 가지게 설정되었으며, 이는 대리인의 창의적 노력의 투입을 관리 감독하는 것이 대리인의 일상적 노력의 투입을 관리 감독하는 것보다 상대적으로 더 어렵다는 것을 전제로 하고 있다[12].

대리인의 행위에 관한 시그널 $y$ 는 대리인이 투입한 일상적 노력 $e_{1}$ 의 수준에 관해 보다 유용한 정보를 제공할 수 있지만, 대리인이 투입한 창의적 노력 $e_{2}$ 의 수준에 대해 덜 유용한 정보를 제공하는 것으로 해석할 수 있다. 창의적 노력에 대한 산출물의 민감도 $\lambda$ 는 산출물을 창출함에 있어 창의적 노력의 중요성을 대변하는 반면, 일상적 노력에 대한 산출물의 민감도는 1 이다. 따라서 $\lambda$ 과 1 의 차이가 크면 클수록, 대리인의 행위에 관한 시그널 $y$ 에 기초하여 대리인을 보상하는 행위통제방식은 그 유용성이 적으므로 산출물의 결과에 입각하여 대리인을 보상하는 방식이 더 유용할 것이다[10]. 다시 말해, $\lambda$ 과 1 의 차이가 큰 경우 대리인의 행위에 관한 시그널 $y$ 에 기초하여 보상하는 방식인 행위통제는 대리인의 창의적 노력을 이끌어냄에 있어 대리인에게 부합할 수 있는 유인을 적절히 제공할 수 없기 때문이다[12].

대리인 이론에 입각하여 주인이 대리인에게 제시할 보상계약을 설계하기 위한 단계별 순서는 다음과 같다. 먼저 주인은 대리인의 행위에 관한 시그널 $y$ 를 획득하기 위해 감독자의 관리감독의 수준인 $\mathrm{m}$ 을 결정한다. 다음 단계에서는, 주인은 다음의 두 가지의 제약조건을 고려하여 자신의 순효용을 극대화할 수 있는 보상계약을 설계한다: (1) 유인부합성 제약조건(incentive compatibility constraint, IC 제약조건): 보상계약은 대리인이 바람직한 수준의 일상적 노력과 창의적 노력을 투입하는 것이 그의 유인과 부합하여야 한다. (2) 개인적 합리성 제약조건(individual rationality constraint, IR constraint): 주인이 제시한 보상계약은 대리인이 그 계약을 수락한 경우 대리인에게 최소한 그의 유보효용(reservation utility)이상을 보장할 수 있어야 한다[5][7][13].

다음 절에서는 주인의 입장에서 대리인에게 제공하게 될 보상계약을 설계함에 있어 보상계약은 $y$ 또는 $x$ 와 선형관계를 가지며, 대리인의 효용은 절대위험회피도(absolute risk aversion)의 계수가 $R$ 인 지수효용함수(exponential utility function)로 나타나며, 대리인의 유보효용은 $r$ 로 가정하고서 각 통제시스템 하에서 보상계약을 유도한다[13]. 이와 같은 가정들을 분석모형에 부과하게 되는 주된 이유는 분석모형의 해(solution)를 구하기 위한 수학적 취급용이성(mathematical tractability)에 기인한 것이다.

\section{2 행위통제 하에서의 보상계약}

행위통제 하에서 대리인에게 제공할 보상계약은 대리인의 행위에 관한 감독자의 관리감독 시그널 $y$ 의 선형함수로 다음과 같이 정의한다: $\Phi_{0}\left(y\left(e_{1}, e_{2}\right)\right)=\alpha+\alpha_{y} y\left(e_{1}, e_{2}\right)$, 여기서 $\alpha$ 는 대리인에게 제공되는 고정급여, $\alpha_{y}$ 은 대리인의 행위에 관한 시그널 $y$ 에 대한 대리인 보상의 민감도이다. 이 경우 대리인의 확실성등가(certainty equivalent: $\mathrm{CE}$ )는 다음과

$$
\text { 같다. } \begin{aligned}
C E\left[\Phi_{0}\left(y\left(e_{1}, e_{2}\right)\right)\right] & =E\left[\Phi_{0}\left(y\left(e_{1}, e_{2}\right)\right)\right]-\frac{R V a r\left[\Phi_{0}\left(y\left(e_{1}, e_{2}\right)\right)\right]}{2}-C\left(e_{1}, e_{2}\right) \\
& =\alpha+\alpha_{y}\left(e_{1}+e_{2}\right)-R \alpha_{y}^{2} \sigma_{y}^{2}(m) / 2-c_{1} e_{1}^{2} / 2-c_{2} e_{2}^{2} / 2 .
\end{aligned}
$$


행위통제 하에서 보상계약을 정의하기 위해서는 백워드 인덕션(backward induction)을 적용하여, 먼저 주인의 입장에서 대리인에게 제공할 보상계약을 어떻게 설계할 것인가의 문제를 푼 후에 다음 단계에서 주인의 입장에서 대리인의 행위에 관한 시그널을 확보하기 위한 감독자의 관리감독의 수준인 $\mathrm{m}$ 을 결정할 것인가의 문제를 검토한다. 따라서 제 1 단계인 대리인에게 제공할 보상계약의 설계에 관한 주인의 문제는 다음 식 (1)로 정의한다.

$\underset{\left\{\alpha, \alpha_{y}, e_{1}, e_{2}\right\}}{\operatorname{Maximize}} E\left[x\left(e_{1}, e_{2}\right)-\Phi_{0}\left(y\left(e_{1}, e_{2}\right)\right)\right]$

s.t. $C E\left[\Phi_{0}\left(y\left(e_{1}, e_{2}\right)\right)\right] \geq r,\left(e_{1}, e_{2}\right)=\underset{\left\{\hat{e}_{1}, \hat{e}_{2}\right\}}{\operatorname{argmax}} C E\left[\Phi_{0}\left(y\left(\hat{e}_{1}, \hat{e}_{2}\right)\right)\right]$

제 1 단계에서 주인이 선택한 관리감독의 수준을 $\mathrm{m}$ 이라고 가정하고서, 행위통제 하에서의 주인이 대리인에게 제공할 보상계약 설계의 문제인 식 (1)의 해를 구하면 다음과 같다:

(i) 선형 보상식의 $\alpha_{y}(m)$ 는 $\frac{c_{2}+\lambda c_{1}}{c_{2}+c_{1}+c_{1} c_{2} R \sigma_{y}^{2}(m)}$,

(ii) 기대산출물 $X_{0}(m) \equiv E\left[x\left(e_{1}, e_{2}\right)\right]$ 는 $\frac{\left(c_{2}+\frac{\left.\lambda c_{1}\right)^{2}}{c_{1} c_{2}}\right)}{c_{2}+c_{1}+c_{1} c_{2} R \sigma_{y}^{2}(m)}$,

(iii) 주인의 기대이익 $\Pi_{0}(m) \equiv E\left[x\left(e_{1}, e_{2}\right)-\Phi_{0}\left(y\left(e_{1}, e_{2}\right)\right)\right]$ 은 $\frac{\left(c_{2}+\lambda c_{1}\right)^{2} /\left(2 c_{1} c_{2}\right)}{c_{2}+c_{1}+c_{1} c_{2} R \sigma_{y}^{2}(m)}-r$.

위의 식 (1)의 해로부터 구한 기대산출물과 주인의 이익 각각에 대해 감독자의 관리감독의 수준인 $\mathrm{m}$ 에 관해 미분을 해보면 다음 결과를 얻는다: $d X_{0}(m) / d m>0$, $d \Pi_{0}(m) / d m>0$. 이는 주인이 감독자의 관리감독의 수준인 $\mathrm{m}$ 을 증가시킬수록 기대산출물과 주인의 기대이익은 증가하는 것을 의미하는 것으로, 관리감독의 수준인 $\mathrm{m}$ 을 증가하면 그로 인해 보상계약의 변수인 관리감독 신호의 정확성(precision)을 개선하여 궁극적으로 도덕적 해이 문제와 관련하여 발생하게 되는 대리인비용(agency cost)을 줄이기 때문이다[7].

제 2 단계에 해당하는 주인의 문제는 감독자의 관리감독의 최적 수준을 결정하는 것으로 다음 식으로 정의된다: $m_{0}=\underset{\{m\}}{\operatorname{argmax}} \Pi_{0}(m)-D(m)$. 이미 본 분석모형에서는 $d \sigma_{y}^{2}(m) / d m<0, d^{2} \sigma_{y}^{2}(m) / d m^{2} \geq 0, d D(m) / d m>0, d^{2} D(m) / d m^{2} \geq 0$ 을 가정하였기 때문에 제 2 단계의 주인의 문제에 대해 유일한 해인 감독자의 관리감독의 최적 수준이 존재한다.

\section{3 행위통제와 결과통제를 동시에 실행하는 상황에서의 보상계약}

행위통제와 결과통제를 동시에 실행하는 통제시스템에서는 대리인에게 제공할 보상계약은 대리인의 행위에 관한 시그널 $y$ 과 산출물 $x$ 의 선형함수로 다음과 같이 정의한다: $\Phi_{I}\left(y\left(e_{1}, e_{2}\right), x\left(e_{1}, e_{2}\right)\right)=\beta+\beta_{y} y\left(e_{1}, e_{2}\right)+\beta_{x} x\left(e_{1}, e_{2}\right)$, 여기서 $\beta$ 는 대리인에게 제공되는 고정급여, $\beta_{y}$ 은 행위통제를 대변하는 대리인의 행위에 관한 시그널 $y$ 에 대한 대리인 보상액의 민감도, $\beta_{x}$ 은 결과통제를 대변하는 산출물 $x$ 에 대한 대리인 보상액의 민감도를 나타낸다. 이 경우 대리인의 확실성등가(certainty equivalent: $\mathrm{CE}$ )는 다음과 같다: $C E\left[\Phi_{I}\left(y\left(e_{1}, e_{2}\right), x\left(e_{1}, e_{2}\right)\right)\right]=\beta+\beta_{y}\left(e_{1}+e_{2}\right)+\beta_{x}\left(e_{1}+\lambda e_{2}\right)$

$$
-R\left[\beta_{y}^{2} \sigma_{y}^{2}(m)+\beta_{x}^{2} \sigma_{x}^{2}+2 \beta_{x} \beta_{y} \sigma_{x y}\right] / 2-c_{1} e_{1}^{2} / 2-c_{2} e_{2}^{2} / 2
$$


행위통제 하에서 보상계약을 정의한 방식과 마찬가지로, 백워드 인덕션(backward induction)을 적용하여 먼저 주인의 입장에서 대리인에게 제공할 보상계약을 어떻게 설계할 것인가의 문제를 푼 후에 다음 단계에서 주인의 입장에서 대리인의 행위에 관한 시그널을 확보하기 위한 감독자의 관리감독의 수준인 $\mathrm{m}$ 을 결정할 것인가의 문제를 검토한다. 따라서 제 1 단계인 대리인에게 제공할 보상계약의 설계에 관한 주인의 문제는 다음 식 (2)로 정의된다.

$\underset{\left\{\beta, \beta_{y}, \beta_{x}, e_{1}, e_{2}\right\}}{\operatorname{aximize}} E\left[x\left(e_{1}, e_{2}\right)-\Phi_{I}\left(y\left(e_{1}, e_{2}\right), x\left(e_{1}, e_{2}\right)\right)\right]$

s.t. $C E\left[\Phi_{I}\left(y\left(e_{1}, e_{2}\right), x\left(e_{1}, e_{2}\right)\right)\right] \geq r,\left(e_{1}, e_{2}\right)=\underset{\left\{\hat{e}_{1}, \hat{e}_{2}\right\}}{\operatorname{argmax}} C E\left[\Phi_{I}\left(y\left(\hat{e}_{1}, \hat{e}_{2}\right), x\left(\hat{e}_{1}, \hat{e}_{2}\right)\right)\right]$

제 1 단계에서 주인이 선택한 감독자의 관리감독의 수준을 $m$ 이라고 가정하고서, 행위통제와 결과통제를 동시에 실행하는 경우에 주인이 대리인에게 제공할 보상계약 설계의 문제인 식 (2)의 해를 구하면 다음과 같다:

(i) 선형 보상식의 $\beta_{y}(m)$ 는 $\frac{\left(c_{2}+\lambda^{2} c_{1}\right)\left(c_{1} c_{2} R \sigma_{x y}+c_{2}+\lambda c_{1}\right)-\left(c_{2}+\lambda c_{1}\right)\left(c_{2}+\lambda^{2} c_{1}+c_{1} c_{2} R \sigma_{x}^{2}\right)}{\left(c_{1} c_{2} R \sigma_{x y}+c_{2}+\lambda c_{1}\right)^{2}-\left(c_{1} c_{2} R \sigma_{x}^{2}+c_{2}+\lambda^{2} c_{1}\right)\left(c_{2}+c_{1}+c_{1} c_{2} R \sigma_{y}^{2}(m)\right)^{\prime}}$

(ii) 선형 보상식의 $\beta_{x}(m)$ 는 $\frac{\left(c_{2}+\lambda c_{1}\right)\left(c_{1} c_{2} R \sigma_{x y}+c_{2}+\lambda c_{1}\right)-\left(c_{2}+\lambda^{2} c_{1}\right)\left(c_{2}+c_{1}+c_{1} c_{2} R \sigma_{y}^{2}(m)\right)}{\left(c_{1} c_{2} R \sigma_{x y}+c_{2}+\lambda c_{1}\right)^{2}-\left(c_{1} c_{2} R \sigma_{x}^{2}+c_{2}+\lambda^{2} c_{1}\right)\left(c_{2}+c_{1}+c_{1} c_{2} R \sigma_{y}^{2}(m)\right)^{\prime}}$

(iii) 기대산출물 $X_{I}(m) \equiv E\left[x\left(e_{1}, e_{2}\right)\right]$ 는 $\frac{\left[\beta_{y}(m)\left(c_{2}+\lambda c_{1}\right)+\beta_{x}(m)\left(c_{2}+\lambda^{2} c_{1}\right)\right]}{c_{1} c_{2}}$,

(iv) 주인의 기대이익 $\Pi_{I}(m) \equiv E\left[x\left(e_{1}, e_{2}\right)-\Phi_{I}\left(y\left(e_{1}, e_{2}\right), x\left(e_{1}, e_{2}\right)\right)\right]$ 은

$$
\left[\beta_{y}(m)\left(c_{2}+\lambda c_{1}\right)+\beta_{x}(m)\left(c_{2}+\lambda^{2} c_{1}\right)\right] /\left(2 c_{1} c_{2}\right)-r \text {. }
$$

위의 식 (2)의 해로부터 구한 기대산출물과 주인의 기대이익 각각에 대해 감독자의 관리감독의 수준인 $\mathrm{m}$ 에 관해 미분을 해보면 다음 결과를 얻는다: $d X_{I}(m) / d m>0$, $d \Pi_{I}(m) / d m>0$. 주인이 행위통제만을 이용하는 경우와 마찬가지로, 이와 같은 결과는 주인이 감독자의 관리감독의 수준인 $\mathrm{m}$ 을 증가시킬수록 기대산출물과 주인의 기대이익은 증가하는 것을 의미하는 것으로, 감독자의 관리감독의 수준인 $\mathrm{m}$ 을 증가하면 그로 인해 보상계약의 변수 중 하나인 관리감독 신호의 정확성(precision)을 개선하여 궁극적으로 도덕적 해이 문제와 관련하여 발생하게 되는 대리인비용(agency cost)을 줄이기 때문이다[7].

제 2 단계에 해당하는 주인의 문제는 감독자의 관리감독의 최적 수준을 결정하는 것으로 다음 식으로 정의된다: $m_{I}=\underset{\operatorname{argmax}}{\arg \Pi_{I}}(m)-D(m)$. 제 2 단계의 주인의 문제에 대해 유일한 해인 관리감독의 최적 수준이 존재한다.

\section{4 행위통제에 의한 보상계약과 행위통제와 결과통제에 의한 보상계약 간의 비교}

대리인이론에 의하면 행위통제만을 활용하여 대리인의 보상계약을 설계하는 경우에 비해 행위통제와 결과통제를 동시에 이용하여 대리인의 보상계약을 설계하면 주인의 순효용은 증가한다[7]. 이는 보상계약에 추가로 포함되는 산출물은 대리인이 투입한 노력의 수준에 대한 유용한 정보를 제공하게 되는 시그널의 역할을 수행하기 때문이다. 최적의 보상계약을 설계하는 제 1 단계에서 주인이 선택한 감독자의 관리감독의 수준을 $\mathrm{m}$ 이라고 한다면, 주인의 기대산출물과 기대이익은 행위통제와 결과통제를 동시에 사용하는 경우에 더 크게 나타난다. 즉, $X_{I}(m) \geq X_{0}(m), \Pi_{I}(m) \geq \Pi_{0}(m)$.

만약 창의적 노력에 대한 산출물의 민감도(즉, 창의적 노력의 한계산출물)과 창의적 노력에 대한 대리인 행위 시그널의 민감도인 1 과 충분히 차이를 보인다면, 주인이 
행위통제와 결과통제를 동시에 사용하는 경우 감독자의 관리감독의 수준 $\mathrm{m}$ 을 증가시킬수록 기대산출물과 기대이익으로 측정할 수 있는 주인의 한계적 혜택(marginal benefit)은 서서히 감소하게 된다. 이를 식으로 표현하면 다음과 같다: $d\left(X_{I}(m)-\right.$ $\left.X_{0}(m)\right) / d m \leq 0, d\left(\Pi_{I}(m)-\Pi_{0}(m)\right) / d m \leq 0$.

주인이 행위통제만을 사용하건 행위통제와 결과통제를 동시에 사용하건 간에 관계없이 대리인의 행위에 대한 감독자의 관리감독의 수준을 증가시킬수록 어느 경우이건 간에 주인의 기대산출물과 기대이익은 증가하게 된다[7]. 그러나, 대리인의 행위에 대한 감독자의 관리감독의 수준을 증가시킴에 따라 주인의 한계적 혜택은 행위통제만을 사용하는 경우와 행위통제와 결과통제를 동시에 사용하는 경우 각각에 대해 상이할 것이다. 창의적 노력에 대한 산출물의 민감도 $\lambda$ 와 창의적 노력에 대한 관리감독 시그널(monitoring signal)의 민감도 1 간의 간격이 클수록, 그만큼 더 관리감독 시그널이 대리인이 투입한 창의적 노력의 수준을 올바르게 대변하기 어렵기 때문이다[4]. 높은 수준의 창의적 노력을 투입하게 유도함으로써 보다 높은 산출물을 이끌어 내기 위한 수단으로서 대리인의 행위에 대한 관리감독 시그널은 목표불일치(goal incongruence)의 정도를 더 크게 만든다[10][12]. 따라서 주인이 행위통제와 결과통제를 동시에 사용할 경우에는 관리감독의 수준을 증가하면 할수록 그로 인한 주인의 한계적 혜택은 더 줄어들기 때문에, 관리감독의 최적 수준은 행위통제만을 사용하는 경우 보다 낮을 것이다. 만약 창의적 노력에 대한 산출물의 민감도와 창의적 노력에 대한 대리인 행위 시그널의 민감도인 1 과 충분히 차이를 보인다면, 행위통제만을 사용한 경우의 관리 감독의 최적 수준 $m_{0}$ 은 행위통제과 결과통제를 동시에 사용한 경우의 관리감독의 최적 수준 $m_{I}$ 보다 크게 나타날 것이다[10].

\section{4. 결론}

본 연구에서는 먼저 조직통제이론과 대리인이론에서 논의된 통제시스템과 보상계약의 연계를 어떻게 하는 것이 조직의 성과를 극대화할 수 있는지에 대해 검토하였다. 구체적으로, 선행연구에서 구체적으로 고려하지 않았던 판매조직 및 판매직원 업무 특성, 판매직원의 성과창출과 관련하여 요구되는 투입요소인 노력의 특성, 감독자의 관리감독 기능, 통제시스템의 역할, 보상계약의 설계 등의 상호작용을 분석모형에 입각하여 살펴보았다는 점은 본 연구의 공헌이라 할 수 있다.

본 연구의 분석결과는 판매조직의 성과관리와 관련하여 다음과 같은 활용방안에 대한 시사점을 제공할 수 있을 것이다. 첫째, 판매조직의 유형에 따라서 그 조직의 산출물에 영향을 미칠 수 있는 판매직원의 노력은 상이하게 정의된다. 특히 고객서비스가 중요한 하이엔드 판매조직에서는 판매직원의 업무 중 표준화된 일상적 서비스보다는 고객지향적 서비스를 이끌어내는 것이 중요하며, 이를 위해서는 낮은 수준의 감독자의 관리감독을 유지함으로써 판매직원의 자율성을 이끌어낼 수 있는 통제시스템과 보상계약을 활용할 필요가 있다. 구체적으로, 하이엔드 판매조직에서는 낮은 수준의 관리감독에 의한 행위통제와 더불어 판매직원의 산출물에 입각한 결과통제 방식은 혼용하는 것이 타당할 것이다. 그 이유는 하이엔드 판매조직에서 성과를 유발하는 요인은 판매직원이 업무의 과정에 투입하게 될 노력의 유형 중 일상적 노력보다는 창의적 노력이 중요하기 때문이다. 이와 같은 조직에서 판매직원의 창의적 노력을 최적화하기 위해서는 보다 많은 의사결정 권한이 판매직원에게 위임되어야 함을 의미한다. 판매직원의 창의적 
노력은 감독자의 관리감독에 의해 개선될 가능성이 낮으며, 판매직원의 내재적 능력과 동기에 의해 결정된다고 보는 것이 타당하기 때문이다.

둘째, 로우엔드 판매조직에서는 단순히 감독자의 관리감독 기능을 강화하는 행위통제 방식에 의존하는 것도 고려해 볼 수 있으며, 판매직원의 산출물을 정확히 측정할 수 있다면 높은 수준의 관리감독을 유지하는 행위통제와 더불어 결과통제로서 산출물에 입각한 금전적 유인을 제공하는 것도 의미가 있을 것으로 판단된다.

셋째, 감독자의 관리감독을 통한 행위통제와 금전적 유인을 통한 결과통제가 동시에 실행되는 경우, 고객서비스의 수월성을 강조하는 하이엔드 판매조직에서는 감독자의 관리감독 기능을 강화하게 되면, 판매직원은 창의적 노력의 수준을 줄이는 대신 감독자가 관찰가능한 일상적 노력에 집중하는 결과를 가져올 가능성이 높다. 따라서 하이엔드 판매조직에서 행위통제와 결과통제를 동시에 실행하는 경우 감독자의 관리감독 수준이 성과에 미치는 부정적 영향이 금전적 유인으로 인한 긍정적 영향을 압도하기 하기 때문에, 두 통제시스템 간의 상호작용 효과는 부(-)로 나타나게 된다. 이와 같은 두 통제시스템 간의 상호작용 효과는 선행연구에 의해 제기된 대체효과 또는 상호보완 효과와는 다른 것으로 해석된다.

본 연구는 단순화된 주인-대리인 모형에 입각하여 통제시스템이 판매조직의 성과에 미치는 영향을 분석하였으며, 특히 하이엔드 판매조직에서는 두 통제시스템 간에 상호작용 효과가 부(-)로 나타나고 있음을 분석적으로 보여주었다는 데 그 의의를 찾을 수 있을 것이다. 그러나 본 연구는 다음과 같은 한계점을 가지고 있다. 첫째, 본 연구의 분석모형은 대리인이 투입하는 두 가지 유형의 노력, 대리인의 노력에 대한 감독자의 관리감독 시그널 및 산출물에 초점을 맞추어, 그 변수들 간의 관계만을 분석함으로써 본 연구의 결과를 일반화하는 데는 한계점이 있을 수 있다. 따라서 앞으로의 후속연구에서는 보다 다양한 변수를 포함한 연구를 수행함으로써 보다 일반화된 연구결과가 제시될 수 있기를 기대한다. 둘째, 본 연구에서 제시한 분석적 결과의 타당성을 입증하기 위해서는 다양한 판매조직을 대상으로 설문지를 이용한 데이터, 판매관리자 및 판매직원을 대상으로 한 인터뷰 데이터, 현장 데이터(field data)등의 수집이 요구된다. 이와 같이 수집한 실제 데이터를 이용한 실증분석을 통해 본 연구에서 제시된 분석결과는 추가로 수정 및 보완이 필요할 것이다.

\section{5. 감사의 글}

이 논문은 2018년도 성신여자대학교 학술연구조성비 지원에 의하여 연구되었음

\section{References}

[1] Z. Fatima, M. K. Azam, The Consequences of Behaviour Based and Outcome Based Salesforce Control Systems, FIIB Business Review, (2017), Vol.6, No.1, pp.56-67, https://doi.org/10.1177/2455265820170108

[2] R. M. Verburg, A. M. Nienaber, R. H. Searle, A. Weibel, D. N. D. Hartog, D. E. Rupp, The Role of Organizational Control Systems in Employees' Organizational Trust and Performance Outcomes, Group \& Organization Management, (2018), Vol.43, No.2, pp.179-206, https://doi.org/10.1177/1059601117725191

[3] V. Sihag, S. A. Rijsdijk, Organizational Controls and Performance Outcomes: A Meta-Analytic Assessment and Extension, Journal of Management Studies, (2019), Vol.56, No.1, pp.91-133, https://doi.org/10.1111/joms.12342 
[4] G. Wang, W. Dou, N. Zhou, The Interactive Effects of Sales Force Controls on Salespeople Behaviors and Customer Outcomes, Journal of Selling \& Sales Management, (2012), Vo.32, No.2, pp.225-243, https://doi.org/10.2753/PSS0885-3134320204

[5] D. Lo, M. Ghosh, F. LaFontaine, The Incentive and Selection Roles of Sales Force Compensation Contracts, Journal of Marketing Research, (2011), Vol.48, No.4, pp.781-798, https://doi.org/10.1509/jmkr.48.4.781

[6] C. P. Cerasoli, J. M. Nicklin, M. T. Ford, Intrinsic Motivation and Extrinsic Incentives Jointly Predict Performance: A 40-Year Meta-Analysis, Psychological Bulletin, (2014), Vol.140, No.4, pp.980-1008, DOI: 10.1037/a0035661

[7] I. Macho-Stadle, D. Pérez-Castrillo, Principal-Agent Models. In: M. Sotomayor, D. Pérez-Castrillo, F. Castiglione, (eds), Complex Social and Behavioral Systems: Game Theory and Agent-Based Models (Encyclopedia of Complexity and Systems Science Series), (1st ed), Springer, (2020)

[8] R. D. Banker, S. Y. Lee, G. Potter, D. Srinivasan, The Impact of Supervisory Monitoring on High-End Retail Sales Productivity, Annals of Operations Research, (2010), Vol.173, No.1, pp.25-37, DOI:10.1007/s10479-009-0572-x

[9] D. Campbell, M. J. Epstein, F. A. Martinez-Jerez, The Learning Effects of Monitoring, The Accounting Review, (2011), Vol.86, No.6, pp.1909-1934.

[10] R. D. Banker, S. Fang, S. Y. Lee, Conflict between Supervisory Monitoring and Monetary Incentives, (2018), http://dx.doi.org/10.2139/ssrn.3232151

[11] M. H. Christ, K. L. Sedatole, K. L. Towry, Sticks and Carrots: The Effect of Contract Frame on Effort in Incomplete Contracts, The Accounting Review, (2012), Vol.87, No.6, pp.1913-1938.

[12] S. J. Kachelmeier, M.G. Williamson, Attracting Creativity: The Initial and Aggregate Effects of Contract Selection on Creativity-Weighted Productivity, The Accounting Review, (2010), Vol.85, No.5, pp.1669-1691, DOI:10.2308/ACCR.2010.85.5.1669

[13] C. Schmitz, Y. C. Lee, G. L. Lilien, Cross-Selling Performance in Complex Selling Contexts: An Examination of Supervisory- and Compensation-Based Controls, Journal of Marketing, (2014), Vol.78 No.5, pp.1-19, https://doi.org/10.1509/jm.12.0421 